\title{
Early Infant Feeding and Adiposity Risk: From Infancy to Adulthood
}

\author{
Wendy H. Oddy ${ }^{a}$ Trevor A. Mori ${ }^{b}$ Rae-Chi Huang ${ }^{a}$ Julie A. Marsh ${ }^{a}$ \\ Craig E. Pennell ${ }^{c}$ Paola T. Chivers ${ }^{d}$ Beth P. Hands ${ }^{d}$ Peter Jacoby ${ }^{a}$ \\ Peter Rzehak $^{\mathrm{e}}$ Berthold V. Koletzko ${ }^{\mathrm{e}}$ Lawrence J. Beilin ${ }^{\mathrm{b}}$

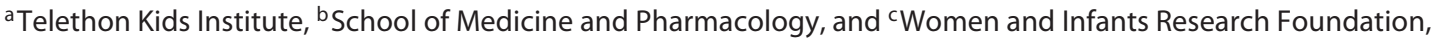

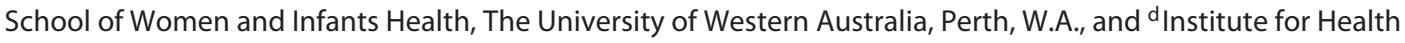 \\ Research, The University of Notre Dame, Fremantle, W.A., Australia; ${ }^{\circ}$ Division of Metabolic and Nutritional Medicine, \\ Dr. von Hauner Children's Hospital, University of Munich Medical Centre, Munich, Germany
}

\section{Key Points}

- Stopping breast-feeding before 6 months may lead to an increased risk of overweight and obesity later in life.

- Introducing a milk other than breast milk before 6 months may lead to an increased risk of obesity 20 years later.

\section{To Summarize Our Current Knowledge}

- Overweight infants are more likely to become overweight children, adolescents, and adults.

- Breast-feeding, preferably of long duration and for at least 6 months and beyond, and late introduction of formula milk are recommended for protection against increased adiposity in childhood, adolescence, and adulthood.

- Increasing the prevalence of exclusive breast-feeding to 6 months would be a worthwhile public health measure.

- A possible adverse effect of formula feeding on postnatal weight gain and infant health remains of contemporary public health significance.

\section{Key Words}

Adiposity · Breast-feeding · Formula-feeding · Obesity ·

Raine Study

\section{Abstract \\ Introduction: Systematic reviews suggest that a longer du- ration of breast-feeding is associated with a reduction in the risk of later overweight and obesity. Most studies examining}

breast-feeding in relation to adiposity have not used longitudinal analysis. In our study, we aimed to examine early infant feeding and adiposity risk in a longitudinal cohort from birth to young adulthood using new as well as published data. Methods: Data from the Western Australian Pregnancy Cohort (Raine) Study in Perth, W.A., Australia, were used to examine associations between breast-feeding and measures of adiposity at 1, 2, 3, 6, 8, 10, 14, 17, and 20 years. $\boldsymbol{R} \boldsymbol{e}$ sults: Breast-feeding was measured in a number of ways.

\section{KARGER}

E-Mail karger@karger.com

www.karger.com/anm
(C) 2014 S. Karger AG, Basel

0250-6807/14/0644-0262\$39.50/0
Prof. Wendy H. Oddy

Telethon Kids Institute

PO Box 855 West Perth

Perth, WA 6874 (Australia)

E-Mail Wendy.Oddy@ telethonkids.org.au 
Longer breast-feeding (in months) was associated with reductions in weight $z$-scores between birth and 1 year $(\beta=$ $-0.027 ; p<0.001)$ in the adjusted analysis. At 3 years, breastfeeding for $<4$ months increased the odds of infants experiencing early rapid growth (OR 2.05; 95\% Cl 1.43-2.94; $\mathrm{p}<$ 0.001 ). From 1 to 8 years, children breast-fed for $\leq 4$ months compared to $\geq 12$ months had a significantly greater probability of exceeding the 95th percentile of weight. The age at which breast-feeding was stopped and a milk other than breast milk was introduced (introduction of formula milk) played a significant role in the trajectory of the BMI from birth to 14 years; the 4-month cutoff point was consistently associated with a higher BMI trajectory. Introduction of a milk other than breast milk before 6 months compared to at 6 months or later was a risk factor for being overweight or obese at 20 years of age (OR 1.47; 95\% Cl 1.12-1.93; $p=$ 0.005). Discussion: Breast-feeding until 6 months of age and beyond should be encouraged and is recommended for protection against increased adiposity in childhood, adolescence, and young adulthood. Adverse long-term effects of early growth acceleration are fundamental in later overweight and obesity. Formula feeding stimulates a higher postnatal growth velocity, whereas breast-feeding promotes slower growth and a reduced likelihood of overweight and obesity. Biological mechanisms underlying the protective effect of breast-feeding against obesity are based on the unique composition and metabolic and physiological responses to human milk.

(c) 2014 S. Karger AG, Basel

\section{Introduction}

Metabolic syndrome represents a cluster of risk factors for cardiovascular disease and type 2 diabetes mellitus that includes central adiposity, impaired fasting glucose tolerance, hypertriglyceridemia, decreased high-density lipoprotein cholesterol, hypertension [1], and often a proinflammatory state [2], oxidative stress, and fatty liver disease [3]. Population-based surveys have shown that metabolic risk factors are increasingly prevalent among children and adolescents and progress into adulthood [4]. This phenomenon is increasing worldwide largely as a consequence of the ongoing obesity epidemic [5].

Gale et al. [6] recently showed that formula feeding affects the fat mass in childhood and that, compared to the body composition of breast-fed infants, formula-fed infants had an altered body composition in infancy. Systematic reviews have shown strong associations between early infant feeding and obesity risk [7-9]; however, so-

Short Breast-Feeding Duration and Adiposity Risk ciodemographic, psychological, behavioral, ethnic, and cultural influences also impact childhood obesity emergence [10]. We have reported that breast-feeding protects against childhood obesity in a population cohort [11-13].

In this paper, we collate the evidence of this association between early infant feeding and adiposity risk in a longitudinal analysis from infancy to 20 years of age, with a presentation of already published as well as new data from the West Australian Pregnancy Cohort Study.

\section{Methods}

The West Australian Pregnancy Cohort (Raine) Study commenced in 1989 with the recruitment of 2,900 pregnant women between 16 and 20 weeks of gestation [14]. A total of 2,868 live infants (96\%) available for follow-up at birth provided a wide range of maternal and offspring data during pregnancy and at 1, 2, $3,6,8,10,14,17$, and 20 years of age. The 20 -year follow-up was complete by December 2012.

Exposures

Duration of Breast-Feeding

Diaries were maintained by the mother during the first 3 years of life. The age at which another milk was introduced and the age at which breast-feeding was stopped were recorded, providing good prospectively collected measures of infant feeding as continuous variables in months. Breast-feeding duration was dichotomized using 4 months as the cutoff point, which is consistent with the recommendation of the World Health Organization prior to 2004 for mothers to exclusively breast-feed their infants for 4 months, although this has since been increased to 6 months [15]. Full breast-feeding was defined as breast-feeding without the regular introduction of milk other than breast milk, but it did not preclude the intake of solid foods.

\section{Other Factors}

Comprehensive medical and obstetric data were obtained at recruitment. Questionnaires ascertained demographic information and maternal factors including the usual prepregnancy weight. Antenatal information was obtained from maternal records and maternal height was measured at the first visit. Infant birth weight (in g) and gestational age (GA; in days) were obtained from medical notes. The maternal prepregnancy BMI was calculated as weight $(\mathrm{kg}) /$ height $^{2}(\mathrm{~m})$. Social, demographic, and family data including family income, structure, and parental education during the mother's pregnancy were prospectively collected via questionnaire.

Outcomes Measured at 1-, 2-, 3-, 6-, 8-, 10-, 14-, 17-, and 20-Year Follow-Ups

At the ages of $1,2,3,6,8,10,14$, and 17 years, participants underwent clinical assessment at the Telethon Kids Institute (formerly known as the Telethon Institute for Child Health Research), initially with the primary caregiver and then independently from age 17 years on. At 20 years, participants attended the clinical as- 
sessment at an adult health facility. Weight was measured to the nearest $100 \mathrm{~g}$ using Wedderburn digital chair scales, with children wearing light clothing, and height was measured to the nearest 0.1 $\mathrm{cm}$ with a Holtain stadiometer. The BMI was calculated as weight $(\mathrm{kg}) /$ height $^{2}(\mathrm{~m})$. Additional anthropometric measures at all follow-up visits included calibrated measurements of waist, hip, and arm circumferences and skinfolds (suprailiac, triceps, and abdominal) using Holtain skinfold calipers (Holtain, Crymych, UK). Blood pressure was taken at all follow-up visits according to a standardized methodology and venous blood samples were taken after an overnight fast for serum insulin, glucose, triglycerides, total cholesterol, HDL cholesterol, LDL cholesterol, and high-sensitivity C-reactive protein. HOMA-IR was calculated as insulin $(\mu \mathrm{U} /$ $\mathrm{ml}) \times \operatorname{glucose}(\mathrm{mmol} / \mathrm{l}) / 22.5$. These additional anthropometric and metabolic results have previously been reported [16].

\section{Statistical Analyses}

One Year

At 1 year of age, the population for analysis was defined as unrelated, full-term, singleton births of European descent with no congenital abnormalities. Weights at birth and at 1 year of age were standardized for sex and age (age at birth was represented by a single time point) using WHO growth standards $[17,18]$. These reflect ideal growth patterns in children who have been breast-fed exclusively for 4 months and are still breast-fed at 12 months. Weight $\mathrm{z}$-scores were calculated using the formula $\left[(\mathrm{X} / \mathrm{M})^{\mathrm{L}}-1\right] /$ $(\mathrm{L} \times \mathrm{S})$, where $\mathrm{X}$ is the weight measurement and $\mathrm{L}, \mathrm{M}$, and $\mathrm{S}$ are the age- and sex-specific values for power in the Box-Cox transformation, the median, and the coefficient of variation, respectively [19]. The difference in weight $\mathrm{z}$-scores from 0 to 1 year was calculated as the birth weight $\mathrm{z}$-score minus the 1 -year weight $\mathrm{z}$-score. Fetal sex-specific summary statistics were calculated for maternal anthropometrics, pregnancy, and early-life factors using means and SD for symmetric distributions and medians and interquartile ranges (Q1 to Q3) for asymmetric distributions.

The cross-sectional analysis of the difference in weight z-score from 0 to 1 year was performed using multivariate linear regression. Covariates were selected for the multivariate model using both forward and backward stepwise procedures. Covariates included: maternal (prepregnancy) age, height, weight, and BMI, maternal smoking (at any time during the pregnancy), family income, parity (coded as an ordered categorical variable), pregnancy weight gain up to 34 weeks' gestation, maternal self-reported diabetes and hypertension during pregnancy, GA at birth, and duration of breast-feeding. All analyses were performed using the statistical graphics software R version 2.6.2 [18].

\section{Growth Trajectories to Three Years}

Longitudinal increases in BMI over the first 3 years of life and the influence of breast-feeding duration, maternal prepregnancy BMI, parental educational status, and maternal smoking during pregnancy were analyzed via latent growth mixture modeling (LGMM) (P.R., B.K., and W.H.O.). Using this random-effects extension of a latent class growth curve model, we identified homogeneous subgroups of typical BMI trajectory classes among the heterogeneous individual growth curves. The number of BMI trajectory classes was identified by test statistics. Use of this model allowed the effects of breast-feeding duration and other predictors of our identified typical BMI trajectory classes to be estimated. Detailed information on the LGMM is available [20]. The significance of breast-feeding duration was evaluated by $95 \% \mathrm{CI}$ around the OR and the size of the OR or mean outcomes and related $\mathrm{p}$ values. Gender was not included in any LGMM as WHO standardized BMI SD scores are standardized to age- and sex-specific 'ideal growth'. All statistical analyses were performed using either SAS 9.3 or Mplus 7.1 statistics software.

Years One to Eight

Using the National Center for Health Statistics/Centers for Disease Control and Prevention website (http://www.cdc.gov/ nchs/), the weight-for-length was calculated for 1-year-olds, BMI z-scores were calculated for 3-, 6-, and 8-year-olds, and overweight was defined according to the sex-specific 95th percentiles [11]. Categories of breast-feeding were defined as: never breast-fed, breast-fed for $\leq 4$ months, breast-fed for 5-8 months, breast-fed for 9-12 months, and breast-fed for $>12$ months. These categories were used in mixed-effects models with the BMI z-score as the response variable and age as the explanatory variable. Final models included adjustment for birth weight, GA, ethnicity, sex, maternal BMI, smoking status during pregnancy, parity, and educational level. Generalized estimating equations modeled overweight from the ages of 1 to 8 years using the sets of covariates. $p=0.05$ was considered statistically significant.

\section{At Fourteen Years}

We have reported adiposity rebound, defined as the last minimum (nadir) BMI before a continuous increase with age [21] and calculated in a subset of individuals $(n=171)$ for whom a complete set of BMI data were available for all 8 measured time points (birth to 14 years), based on the child's age in months. We used linear mixed modeling which accounted for correlated errors normally associated with repeated, continuous, and correlated observations. The variables for the age at which breast-feeding was stopped and the age at which another milk was introduced were categorized using a 4-month cutoff point. These were compared across weight status groups [22]. The effect of the duration of breast-feeding (based on the 4-month cutoff point) was assessed across the age range based on group mean differences tested using Pearson's $\chi^{2}$ test. Adjustment for potential socioeconomic status confounding was based on maternal education.

\section{At Seventeen Years}

A longitudinal analysis was performed $(n=1,009)$ using multivariate linear regression models with continuous BMI as the response variable and breast-feeding duration and age at 17 years of age which milk other than breast milk was introduced (in months) as dichotomized explanatory variables, adjusting for child gender and the following maternal factors: prepregnancy BMI, education, age, and family income.

\section{At Twenty Years}

The nonrandom loss of disadvantaged participants is to be expected in a longitudinal cohort and may decrease the generalizability of any findings. We developed a method that could be applied to account for such attrition bias using inverse probability weighting [23].

Our aim was to investigate exclusive breast-feeding and the prevalence of a high BMI, overweight, and obesity at 20 years. Of the original cohort $(n=2,868), 73 \%$ were available at the 20 -year follow-up. Our follow-up response rate was $46 \%$ of those available 
for follow-up $(n=1,053)$. Participants at 20 years were compared to nonparticipants to identify a priori candidates to predict missingness [24]. A missingness model was defined based on sociodemographic factors that predicted continued participation (maternal factors of age, education, BMI before pregnancy, and family income at birth). Final models (i.e. overweight and obesity vs. breast-feeding) incorporated generalized estimating equations and our final predictive model provided an OR and 95\% CI.

\section{Results}

\section{At One Year}

By the time their infant was 6 months of age, 39\% of the mothers had stopped breast-feeding and $55 \%$ had introduced a milk other than breast milk. At 1 year of age, a longer duration of breast-feeding was independently associated with reductions in weight $\mathrm{z}$-scores between birth and the first year of life $(\beta=-0.027$; SE $0.004 ; \mathrm{p}<0.001)$ following adjustment for maternal factors, increasing weight gain up to 34 weeks of gestation, birth order, and duration of gestation (table 1).

\section{At Three Years}

Using BMI SD scores, the growth pattern of infants identified in a class 2 pattern - comprising $35.8 \%$ of the cohort - began at $0.3 \mathrm{SD}$ above the ideal growth standard and gained almost $1 \mathrm{SD}$ within the first 2 years (fig. 1). The curve remained $1 \mathrm{SD}$ above the ideal, normative growth development up to 3 years of age. We showed that breast-feeding for $<4$ months significantly increased the odds of infants being assigned to early rapid growth class 2 (OR 2.05; 95\% CI 1.43-2.94; $\mathrm{p}<0.001$ ) following adjustment for maternal BMI before pregnancy, socioeconomic status, and GA. Although the growth patterns of infants identified in a class 1 or class 3 pattern showed an even stronger increase in BMI SD score deviation from ideal growth within the first 2 years compared to those in class 2 , breast-feeding was not significantly associated with these growth patterns.

\section{At One, Three, Six, and Eight Years}

As reported previously [11], at 1 year infants breastfed for $>12$ months were the leanest group (mean $\mathrm{z}$ score $-0.16,95 \%$ CI -0.28 to -0.04 ; not breast-fed: mean z-score $0.16,95 \%$ CI $0.02-0.29$; breast-fed for $\leq 4$ months: mean z-score $0.31,95 \%$ CI $0.22-0.40$; breastfed for 5-8 months: mean z-score 0.17 , 95\% CI 0.060.27 , and breast-fed for 9-12 months: mean z-score $0.11,95 \%$ CI $0.01-0.22$ ). From 1 to 8 years, children breast-fed for $\leq 4$ months compared to those breast-fed

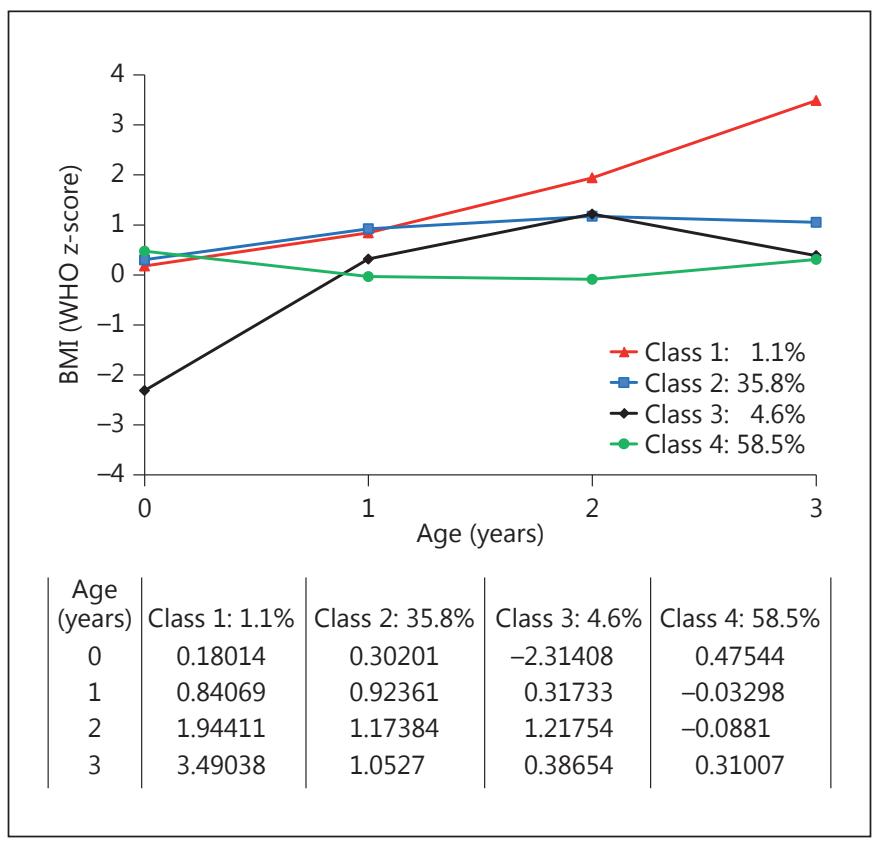

Fig. 1. Identified BMI trajectory classes from birth to 3 years by LGMM in the Raine Study.

Table 1. Analysis of changes in weight $\mathrm{z}$-scores from birth to 1 year

\begin{tabular}{|c|c|c|c|}
\hline & $\begin{array}{l}\text { Esti- } \\
\text { mate }\end{array}$ & SE & $\mathrm{p}$ \\
\hline Length of gestation ${ }^{\mathrm{a}}$ (days) & -0.037 & 0.003 & $<0.001$ \\
\hline \multicolumn{4}{|l|}{ Parity } \\
\hline 0 & 1 & & $<0.001$ \\
\hline 2 & -0.287 & 0.072 & \\
\hline \multicolumn{4}{|l|}{ Maternal smoker } \\
\hline No & 1 & & \\
\hline Yes & 0.319 & 0.056 & $<0.001$ \\
\hline \multicolumn{4}{|l|}{ Maternal diabetes } \\
\hline No & 1 & & \\
\hline Yes & -0.435 & 0.142 & 0.002 \\
\hline \multicolumn{4}{|l|}{ Maternal hypertension } \\
\hline No & 1 & & \\
\hline Yes & 0.123 & 0.057 & 0.031 \\
\hline Pregnancy weight gain ${ }^{\mathrm{a}}$ (kg) & -0.015 & 0.004 & $<0.001$ \\
\hline Prepregnancy maternal $\mathrm{BMI}^{\mathrm{a}}$ & -0.019 & 0.006 & 0.001 \\
\hline Duration of breast-feeding (months) & -0.027 & 0.004 & $<0.001$ \\
\hline \multicolumn{4}{|c|}{ Family income } \\
\hline$<$ AUD 11,999 & 1 & & \\
\hline AUD $12,000-23,999$ & 0.070 & 0.086 & 0.412 \\
\hline AUD 24,000-35,999 & 0.084 & 0.086 & 0.331 \\
\hline$>$ AUD 36,000 & 0.207 & 0.087 & 0.018 \\
\hline
\end{tabular}

${ }^{a}$ Continuous covariates were centered prior to analysis: length of gestation minus 280 days, pregnancy weight gain minus $14 \mathrm{~kg}$, and pre-pregnancy maternal BMI minus $22 \mathrm{~kg} / \mathrm{m}^{2}$. 

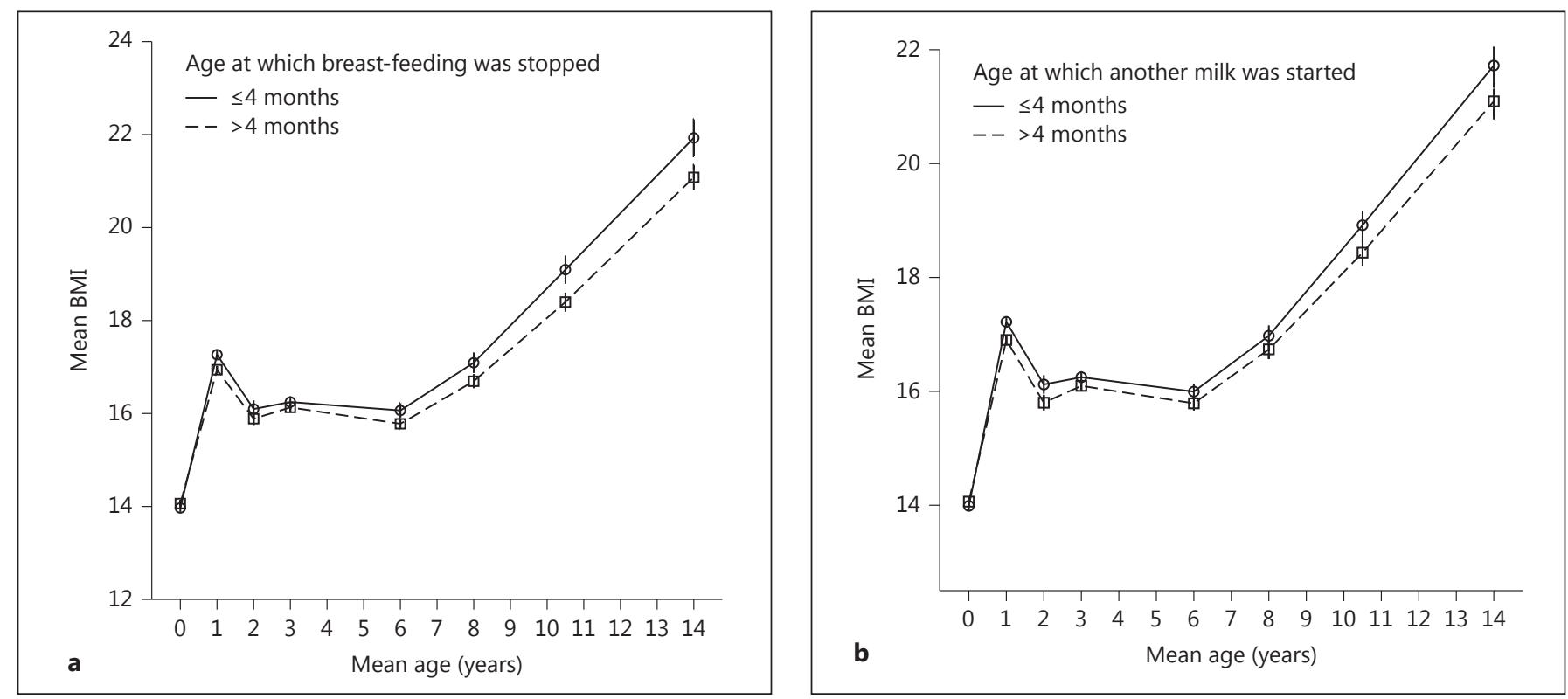

Fig. 2. Mean BMI by mean age based on the age at which breast-feeding was stopped $(\mathbf{a} ; n=1,330)$ and the age at which another milk was introduced $(\mathbf{b} ; \mathrm{n}=1,320)$ [12]. Error bars show 95\% CI of the mean.

for $>12$ months had the greatest probability of exceeding the 95th percentile for BMI (OR 1.87; 95\% CI 1.21$2.89 ; \mathrm{p}=0.005)$, and this was associated with the highest prevalence of maternal obesity, smoking, and lower education.

\section{At Fourteen Years}

The age at which breast-feeding was stopped and a milk other than breast milk was introduced played significant roles in the trajectory of BMI from birth to 14 years, especially at the 4-month cutoff point; differences in BMI peaks were apparent at 1 year of age, and these differences were consistent over time and into adolescence (fig. 2a, b).

\section{At Seventeen Years}

Cessation of breast-feeding before 6 months and introduction of a milk other than breast milk before 6 months compared to at 6 months or later were associated with an increased BMI at 17 years. The BMI was consistently associated with early cessation of breast-feeding following adjustment for gender, maternal age, maternal education, family income at birth, and maternal prepregnancy BMI (table 2).

\section{At Twenty Years}

In recent work [13] at 20 years, our final predictive weighted model showed that cessation of exclusive breast-
Table 2. Multivariate linear regression models for continuous BMI at 17 years, with breast-feeding duration and age at which a milk other than breast milk was introduced (in months), as dichotomized variables

\begin{tabular}{|c|c|c|}
\hline \multicolumn{2}{|c|}{ BMI at 17 years $^{\mathrm{a}}$} & $\mathrm{p}$ value \\
\hline \multicolumn{3}{|c|}{ Breast-feeding stopped by* } \\
\hline 3 months & $1.26(0.43-2.10)$ & 0.003 \\
\hline 4 months & $1.14(0.37-1.92)$ & 0.004 \\
\hline 5 months & $1.01(0.26-1.75)$ & 0.008 \\
\hline 6 months & $0.95(0.23-1.67)$ & 0.100 \\
\hline \multicolumn{3}{|c|}{ Milk other than breast milk was introduced before* } \\
\hline 3 months & $1.17(0.43-1.91)$ & 0.002 \\
\hline 4 months & $1.15(0.45-1.84)$ & 0.001 \\
\hline 5 months & $1.11(0.42-1.80)$ & 0.002 \\
\hline 6 months & $1.07(0.37-1.76)$ & 0.003 \\
\hline
\end{tabular}

feeding before 6 months, compared to at 6 months or later, was associated with an increased prevalence of overweight and obesity (BMI 25+) at 20 years (OR 1.47; 95\% CI 1.12-1.93; $\mathrm{p}=0.005)$. The full multivariate generalized estimating equation model for being overweight or obese 
Table 3. Multivariate generalized estimating equation model for being overweight or obese compared to normal weight at 20 years, by milk introduced before 6 months of age

\begin{tabular}{llc}
\hline Exposures & Overweight or obese at 20 years $^{\mathrm{a}} \mathrm{p}^{\text {value }}$ \\
\hline A milk other than breast milk was introduced before & & 0.005 \\
$\quad \quad 6$ months of age (yes vs. no) & $1.47(1.12-1.93)$ & 0.340 \\
Gender (male vs. female) & $1.14(0.87-1.49)$ & 0.210 \\
Maternal age at birth $(<20$ vs. $\geq 20$ years) & $1.49(0.80-2.80)$ & 0.080 \\
Maternal education $(<12$ vs. $\geq 12$ years) & $1.27(0.97-1.67)$ & 0.030 \\
Family income at birth (<AUD 12,000 vs. $\geq$ AUD 12,000) & $1.59(1.05-2.40)$ & $<0.001$ \\
Maternal BMI before pregnancy ( $\geq 25$ vs. $<25)$ & $3.11(2.22-4.34)$ & \\
\hline
\end{tabular}

The sample was weighted according to principles of inverse probability weighting [23].

${ }^{\text {a }}$ Values represent OR (95\% CI).

compared to normal weight at 20 years, by milk introduced before 6 months of age, is shown in table 3. Supplementary tables provide further information about the West Australian Pregnancy Cohort Study.

\section{Discussion}

Breast-feeding, preferably of a long duration $(>6$ months), and late introduction of formula milk are recommended for protection against increased adiposity in childhood, adolescence, and young adulthood. Our results provide an opportunity to examine the influence of infant feeding on weight status, the relationship with adiposity rebound, and subsequent adolescent and youngadult BMI. Overall, our findings suggest that formula feeding compared to breast-feeding results in accelerated weight gain in the infant, with likely upward BMI centile crossing [25]. Our results support other studies that showed overweight in adolescence increased as the duration of exclusive breast-feeding decreased [26], and they extend the findings of Burke et al. [11] which showed a higher BMI at 8 years in children breast-fed for $\leq 4$ months. Statistical modeling [12] showed that breastfeeding and the age at which another milk was introduced play an important role and may contribute to the timing of the adiposity rebound.

A number of observational studies and meta-analyses have shown small protective effects of breast-feeding on obesity. However, other studies have found no effect and raise the possibility of unknown confounders and publication bias [27]. Three comprehensive meta-analyses were conducted over the past decade. A meta-analysis that included 9 studies with over 69,000 participants [7] showed that breast-feeding has a consistent protective effect against childhood obesity (OR 0.78 ; 95\% CI $0.71-$ 0.85 ), with 4 studies showing a dose-response effect for the duration of breast-feeding. A meta-analysis of 17 studies in 2005 [8] found a dose-response relationship where an increased duration of breast-feeding was related to a decreased risk of overweight later in life. More specifically, that meta-analysis reported a $4 \%$ decrease in risk with each additional month of breast-feeding. When restricted to exclusive breast-feeding, the risk of overweight decreased by $6 \%$ per month [8] suggesting that exclusivity of breast-feeding may be central to the mechanism whereby it protects against obesity [28]. A meta-analysis by Owen et al. [9] concluded that breast-feeding reduces the risk of obesity compared to formula feeding (OR 0.87 ; 95\% CI 0.85-0.89). However, the same authors have since suggested that any observed protective effect of breastfeeding on the BMI may be due to unadjusted confounding [27]. Beyerlein and von Kries [29] suggested that the discrepancy in the findings of studies examining breastfeeding and obesity may be due to the different effects of breast-feeding in normal-weight versus overweight populations, showing a protective effect of breast-feeding in those within the highest BMI percentiles (>90th) [30].

A German study of 9,357 children found that breastfeeding had a protective effect against obesity and overweight which remained significant after adjusting for social class and lifestyle [31]. A dose-response relationship was shown with the duration of breast-feeding, indicating a possible causal effect associated with a shorter duration.

A recent study of 822 young adults (aged 18-28 years) from the Netherlands [32] demonstrated that exclusive breast-feeding had a significant protective dose-response effect on measures of body fat mass and visceral fat mass 
(BMI, waist circumference, and waist-hip ratio). Furthermore, findings from a much smaller prospective randomized controlled trial of preterm infants support a causal link between breast milk feeding and the lipoprotein profile later in life [33].

A crucial period during postnatal growth relating to obesity risk has been hypothesized. The timing of this period remains uncertain, with some suggesting that the first few days of life [34], the first few weeks [28], or up to the first 2 years may be the crucial period [35]. Plausible mechanisms for the development of fatness during this early sensitive window of exposure include permanent structural changes such as a decreased $\beta$-cell mass, accelerated cellular aging, telomere shortening with cell division and oxidative damage, and epigenetic programming changes from transcription to translation of proteins [36]. Our results demonstrate that the early months of life are the crucial period for the development of adiposity later in life.

We showed that, in terms of feeding patterns, the time period of greatest risk for obesity later in life was prior to 6 months, and this finding supports the recommendation of continued exclusive breast-feeding for up to 6 months and beyond. The theory is that a high-nutrient diet in infancy adversely programs the cardio-metabolic system by promoting growth acceleration (upward centile crossing) [37]. Therefore, a slower growth benefits later cardiovascular disease and its risk factors [33]. Early growth acceleration programs the abnormal vascular biology associated with early atherosclerosis. Therefore, infants who grow rapidly during infancy or are at the highest end of the weight or BMI distribution are at an increased risk for subsequent obesity [38]. The growth velocity may have a relevant influence on the causal pathway of obesity, as suggested for fetal programming of metabolic disease [39], with reported associations between protein intake, growth velocity, and weight gain $[40,41]$.

The theory of reverse causation in relation to growth suggests that infants who have lower growth trajectories, and therefore lower energy requirements, are satisfied with breast-feeding for longer. Children 'programmed' to be larger require and demand a higher energy intake, resulting in the mother supplementing with formula or solid food earlier [42]. Rapid growth in the first few months of life leads to an elevated risk of obesity in breast-fed as well as formula-fed infants; however, as breast-feeding has been shown to promote slower growth, obesity is less likely in breast-fed infants $[43,44]$.

Findings from recent randomised controlled studies followed up at 2 and 6 years, respectively [45, 46], com- pared the BMI of infants fed high-protein formula versus low-protein formula and a breast-feeding comparison group and were supportive of the early protein hypothesis. Those authors reported a higher BMI in the high-protein-formula group compared to the low-protein group which had BMI values closer to those of the breast-fed infants. With regard to the risk of later obesity, the most important differences between breast milk and formula appear to be related to the lower protein content and the presence of hormones, growth factors, and bioactive factors in breast milk [47]. In addition, the biological mechanisms underlying the protective effect of breast milk feeding compared to formula feeding are based on the unique composition of human milk and the metabolic and physiological responses to human milk [48]. Breastfed infants may absorb less energy per volume than formula-fed infants, as well as receiving modifying growth factors that may inhibit adipocyte differentiation $[48,49]$.

Evidence exists for programming by nutrition in early infancy [50]. Feeding methods may prime offspring dietary behaviors, possibly by influencing the development of the hypothalamus which occurs through gestation and into the postnatal period and is thought to play an important role in appetite control [51]. In humans, breast-fed babies have been shown to exhibit better appetite control than bottle-fed babies [52]. This evidence supports the link between a longer duration of breast-feeding and a decreased risk of obesity later in life.

\section{Strengths}

Our study has a number of strengths that include the use of a prospective pregnancy cohort and early infant feeding data, and anthropometric data collected for up to 20 years. Breast-feeding data were collected close to the period of breast-feeding cessation and a diary card was maintained to improve data collection. The study design and large community sample are clear strengths, generating adequate statistical power to measure the association between dichotomized breast-feeding variables and anthropometric outcomes while controlling for possible confounders.

\section{Conclusion}

As with other programming effects, the effect of early diet on the later obesity risk may amplify over time. The early postnatal period is a particularly important time for the risk of the development of obesity and its cardiometabolic sequelae which may potentially be addressed 
through the promotion of breast-feeding. Therefore, this period is particularly important for targeting interventions, and our findings suggest that the promotion of breast-feeding may have long-term protective benefits against future obesity.

\section{Acknowledgements}

We gratefully acknowledge the Raine Study participants and their families, and the Raine Study Team for cohort coordination and data collection. Core funding for the Western Australian Pregnancy Cohort (Raine) Study was provided by the University of Western Australia; the Faculty of Medicine, Dentistry and Health Sciences at the University of Western Australia; the Telethon Kids Institute (formerly known as the Telethon Institute for Child Health Research); the Women and Infants Research Foundation; Curtin University of Technology; Edith Cowan University, and the
Raine Medical Research Foundation. We thank the National Health and Medical Research Council (NHMRC) for their provision of funding (project ID No. 1022134 and European Union collaborative project ID No. 1037966). Acknowledgments are extended for NHMRC-funded participation in the European Union project 'Long-Term Effects of Early Nutrition on Later Health' FP7-289346-EarlyNutrition, coordinator: Ludwig Maximilian University of Munich, Germany, project director: Prof. Berthold Koletzko, MD, PhD. The research leading to these results received funding from the European Union's 7th Framework Programme (FP7/2007-2013), EarlyNutrition project, under grant agreement No. 289346. Professor Oddy was awarded an International Visiting Fellowship at the Center for Advanced Studies, University of Munich, in 2013.

\section{Disclosure Statement}

No conflicts of interest are declared.

\section{References}

1 Alberti KGMM, Eckel RH, Grundy SM, Zimmet PZ, Cleeman JI, Donato KA, et al: Harmonizing the metabolic syndrome: a joint interim statement of the International Diabetes Federation Task Force on Epidemiology and Prevention; National Heart, Lung, and Blood Institute; American Heart Association; World Heart Federation; International Atherosclerosis Society, and International Association for the Study of Obesity. Circulation 2009; 120:1640-1645.

2 Hotamisligil GS: Inflammation and metabolic disorders. Nature 2006;444:860-867.

3 Ayonrinde OT, Olynyk JK, Beilin LJ, Mori TA, Pennell CE, de Klerk NH, et al: Gender specific differences in adipose distribution and adipocytokines influence adolescent NAFLD. Hepatology 2011;53:800-809.

4 Camhi SM, Katzmarzyk PT: Tracking of cardiometabolic risk factor clustering from childhood to adulthood. Int J Ped Obesity 2010;5:122-129.

5 Bruce KD, Hanson MA: The developmental origins, mechanisms, and implications of metabolic syndrome. J Nutrition 2010;140: 648-652.

6 Gale C, Logan KM, Santhakumaran S, Parkinson JRC, Hyde MJ, Modi N: Effect of breastfeeding compared with formula feeding on infant body composition: a systematic review and meta-analysis. Am J Clin Nutr 2012;95: 656-669.

-7 Arenz S, Ruckerl R, Koletzko B, von Kries R: Breast-feeding and childhood obesity - a systematic review. Int J Obesity 2004;28:12471256.

8 Harder T, Bergmann RL, Kallischnigg G, Plagemann A: Duration of breastfeeding and risk of overweight: a meta-analysis. Am J Epidemiol 2005;162:397-403.
-9 Owen CG, Martin RM, Whincup PH, Smith GD, Cook DG: Effect of infant feeding on the risk of obesity across the life course: a quantitative review of published evidence. Pediatrics 2005; 115:1367-1377.

10 Schonfeld-Warden N, Warden CH: Pediatric obesity: an overview of etiology and treatment. Pediatr Clin North Am 1997;44:339341.

11 Burke V, Beilin LJ, Simmer K, Oddy WH, Blake KV, Doherty D, et al: Breastfeeding and overweight: longitudinal analysis in an Australian birth cohort. J Pediatr 2005;147:56-61.

12 Chivers P, Hands B, Parker H, Bulsara M, Beilin LJ, Kendall GE, et al: Body mass index, adiposity rebound and early feeding in a longitudinal cohort. Int J Obes 2010;34:1169-1176.

13 Oddy WH, Smith GD, Jacoby P: A possible strategy for developing a model to account for attrition bias in a longitudinal cohort to investigate associations between exclusive breastfeeding and overweight and obesity at 20 years. Ann Nutr Metab 2014, in press.

-14 Newnham JP, Evans SF, Michael CA, Stanley JF, Landau LI: Effects of frequent ultrasound during pregnancy - a randomised controlled trial. Lancet 1993;342:887-891.

15 World Health Organization: Global strategy for infant and young child feeding. Geneva, WHO, 2003.

16 Huang R-C, Mori TA, Burke V, Newnham J, Stanley FJ, Landau LI, et al: Synergy between adiposity, insulin resistance, metabolic risk factors and inflammation in adolescents. Diabetes Care 2009;32:695-701.

17 World Health Organization: WHO child growth standards: methods and development: length/height-for-age, weight-for-age, weightfor-length, weight-for-height and body mass index-for-age. Geneva, WHO, 2006.
18 World Health Organization: Construction of the World Health Organization child growth standards: selection of methods for attained growth curves. Stats Med 2006;25:247-265.

19 Cole TJ: The LMS method for constructing normalized growth standards. Eur J Clin Nutr 1990;44:45-60.

20 Hoyle RH: Handbook of Structural Equation Modeling. New York, Guilford Press, 2012.

21 Rolland-Cachera MF, Deheeger M, Bellisle F, Sempe M, Guilloud-Bataille M, Patois E: Adiposity rebound in children: a simple indicator for predicting obesity. Am J Clin Nutr 1984; 39:129-135.

22 Cole TJ, Bellizzi MC, Flegal KM, Dietz WH: Establishing a standard definition for child overweight and obesity worldwide: international survey. Brit Med J 2000;320:12401243.

23 Seaman SR, White IR: Review of inverse probability weighting for dealing with missing data. Stat Methods Med Res 2013;22:278-295.

24 Miller RB, Hollist CS: Attrition bias; in Salkind N (ed): Encyclopedia of Measurement and Statistics. Thousand Oaks, Sage Reference, 2007, pp 57-60.

25 Cole TJ: Children grow and horses race: is the adiposity rebound a critical period for later obesity? BMC Pediatr 2004;4:6-13.

26 Mayer-Davis EJ, Rifas-Shiman SL, Zhou L, Hu FB, Colditz GA, Gillman MW: Breastfeeding and risk for childhood obesity. Diabetes Care 2006;29:2231-2237.

27 Owen CG, Martin RM, Whincup PH, DaveySmith G, Gillman MW, Cook DG: The effect of breastfeeding on mean body mass index throughout life: a quantitative review of published and unpublished observational evidence. Am J Clin Nutr 2005;82:1298-1307. 
28 Singhal A, Lanigan J: Breastfeeding, early growth and later obesity. Obes Rev 2007;8: 51-54.

-29 Beyerlein A, von Kries RD: Breastfeeding and body composition in children: will there ever be conclusive empirical evidence for a protective effect against overweight? Am J Clin Nutr 2011;94:1772S-1775S.

- 30 Beyerlein A, Toschke AM, von Kries R: Breastfeeding and childhood obesity: shift of the entire BMI distribution or only the upper parts. Obesity 2008;16:2730-2733.

- 31 Koletzko B, von Kries R, Monasterolo RC, Subias JE, Scaglioni S, Giovannini M, et al: Can infant feeding choices modulate later obesity risk? Am J Clin Nutr 2009;89:1502S1508 S.

- 32 De Kroon M, Renders C, Buskermolen M, Van Wouwe J, van Buuren S, Hirasing R: The Terneuzen Birth Cohort: longer exclusive breastfeeding duration is associated with leaner body mass and a healthier diet in young adulthood. BMC Pediatr 2011;11:33.

- 33 Singhal A, Cole TJ, Fewtrell M, Deanfield J, Lucas A: Is slower early growth beneficial for long-term cardiovascular health? Circulation 2004;109:1108-1113.

- 34 Stettler N, Stallings VA, Troxel AB, Zhao J, Schinnar R, Nelson SE, et al: Weight gain in the first week of life and overweight in adulthood: a cohort study of European American subjects fed infant formula. Circulation 2005; 111:1897-1903
-35 Toschke AM, Grote V, Koletzko B, von Kries $\mathrm{R}$ : Identifying children at high risk for overweight at school entry by weight gain during the first two years. Arch Pediatr Adolesc Med 2004; 158:449-452.

36 Druet C, Ong KK: Early childhood predictors of adult body composition. Best Practice Res Clin Endocrinol Metabol 2008;22:489-502.

37 Singhal A, Lucas A: Early origins of cardiovascular disease: is there a unifying hypothesis? Lancet 2004;363:1642-1645.

38 Baird J, Fisher D, Lucas P, Kleijnen J, Roberts $\mathrm{H}$, Law C: Being big or growing fast: systematic review of size and growth in infancy and later obesity. Brit Med J 2005;331:929-935.

39 Lucas A: Programming not metabolic imprinting. Am J Clin Nutr 2000;71:602.

40 Fomon SJ, Ziegler EE, Nelson SE, Frantz JA: What is the safe protein-energy ratio for infant formulas? Am J Clin Nutr 1995;62:358363.

41 Axelsson IE, Ivarsson SA, Raiha NC: Protein intake in early infancy: effects on plasma amino acid concentrations, insulin metabolism, and growth. Pediatr Res 1989;26:614-617.

42 Kramer MS, Guo T, Platt RW, Shapiro S, Collet J, Chalmers B, et al: Breastfeeding and infant growth: biology or bias? Pediatr 2002; 110:343-347.

43 Gillman MW: Early infancy - a critical period for development of obesity. J Dev Orig Health Dis 2010;1:292-299.

-44 Lucas A, Morley R, Cole TJ, Gore SM: A randomised multicentre study of human milk versus formula and later development in preterm infants. Arch Dis Child Fetal Neonatal Ed 1994;70:F141-F146.
45 Grote V, von Kries R, Closa-Monasterolo R, Scaglioni S, Gruszfeld D, Sengier A, et al: Protein intake and growth in the first 24 months of life. J Pediatr Gastroenterol Nutr 2010; 51(suppl 3):S117-S118.

46 Weber M, Grote V, Closa-Monasterolo R, Escribano J, Langhendries J-P, Dain E, et al: Lower protein content in infant formula reduces BMI and obesity risk at school age: follow-up of a randomized trial. Am J Clin Nutr 2014;99:1041-1051.

-47 Savino F, Fissore MF, Liguori SA, Oggero R: Can hormones contained in mothers' milk account for the beneficial effect of breast-feeding on obesity in children? Clin Endocrinol 2009;71:757-765.

48 Hamosh M: Bioactive factors in human milk. Pediatr Clin North America 2001;48:69-86.

49 Garofalo RP, Goldman AS: Cytokines, chemokines, and colony-stimulating factors in human milk: the 1997 update. Biol Neonate 1998;74:134-142.

50 Lucas A: Programming by early nutrition: an experimental approach. J Nutr 1998;128: 401S-406S.

51 Bouret SG: Role of early hormonal and nutritional experiences in shaping feeding behavior and hypothalamic development. J Nutr 2010;140:653-649.

52 Bartok C, Ventura AK: Mechanisms underlying the association between breastfeeding and obesity. Int J Pediatr Obesity 2009;4:196-120. 